\title{
Estrategias translúcidas y contraimágenes: romper con la representación hegemónica*
}

\author{
Haizea Barcenilla García \\ Universidad del País Vasco (UPV/EHU) \\ haizea.barcenilla@ehu.eus
}

RESUMEN: Este artículo estudia dos diferentes estrategias utilizadas por artistas que pertenecen a colectivos vulnerables para subvertir el régimen hegemónico de las imágenes. Las contraimágenes consisten en representaciones que se sitúan más allá de lo aceptable dentro de la normatividad del canon y se posicionan en contraposición a este. Las estrategias translúcidas, en cambio, juegan con la visibilidad y la ocultación, creando imágenes más ambiguas que pueden infiltrarse en el régimen de representación y subvertirlo desde su interior. La combinación de ambas supone una mayor potencialidad de perturbación. Para presentar estas estrategias se utilizan obras de Felix Gonzalez-Torres, Robert Mapplethorpe y el colectivo Señora Polaroiska.

PALABRAS CLAVE: Visibilidad; Homosexualidad; Sida; Feminismo; Arte contemporáneo; Género.

\section{Translucent Strategies and Counter-Images: Breaking up with Predominant Representation}

ABSTRACT: This paper focuses on two strategies used by artists in vulnerable collectives to subvert the predominant system of images. Counter-images are representations that go beyond the acceptable in the logic of canon standards and take up a position against them. Translucent strategies, on the other hand, play with visibility and concealment, and create ambiguous images that can infiltrate the system of representation, and subvert it from the inside. The combination of both can bring about a stronger potential for disruption. To introduce these strategies we use works by z, Robert Mapplethorpe and the Señora Polaroiska collective.

KEYWORDS: Visibility; Homosexuality; AIDS; Feminism; Contemporary Art; Gender.

\section{Rastros en una cama vacía}

En la primavera de 1992, aquellos neoyorquinos que levantaron la mirada del suelo se encontraron con un extraño anuncio en diferentes vallas publicitarias. Sin ningún rótulo que explicara qué se pretendía vender, una imagen en blanco y negro mostraba una cama desecha, en cuyas sábanas y almohadas blancas se percibía el rastro dejado por dos cuerpos [1] y [2]. ¿Era el anuncio de una fábrica de colchones? ¿De un hotel?

A pesar de aparecer en soportes para anuncios, estas imágenes se alejaban de cualquier lógica publicitaria. Se trataba en realidad de Untitled (Sin título), una intervención artística realizada por Felix Gonzalez-Torres que se extendía por 24 diferentes lugares de la Gran Manzana. Al igual que lo hiciera Jenny Holzer con sus Truisms (Truismos) en Times Square en 1982, Gonzalez-Torres invadía espacios enfocados a la persuasión comercial y desviaba su función. Sin embargo, mientras Holzer se centraba en la rotundidad del texto e incluso jugaba con la inmediatez de los eslóganes utilizados en estrategias de marketing, Gonzalez-Torres apostaba a la carta contraria y presentaba una imagen solitaria, independiente de cualquier texto explicativo, cuyo mensaje distaba de ser claro e inmediato. Al contrario que la publicidad, que pretende transmitir mensajes directos, la imagen de la cama revuelta sembraba más dudas que certezas. 


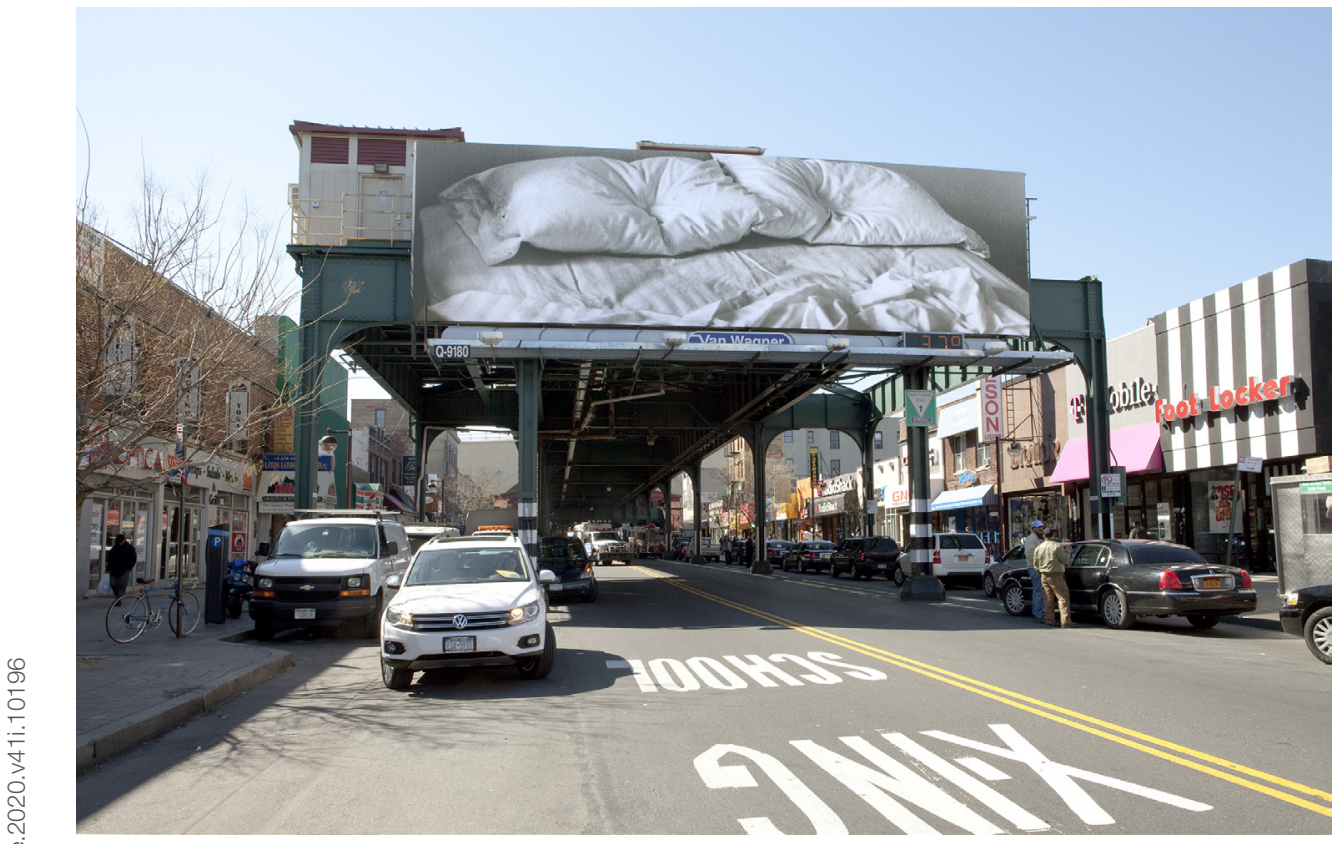

1. Untitled, 1991. Valla publicitaria, dimensiones variables según la instalación, calle 31 cerca de Ditmars Boulevard, Queens, NY. 1 de 6 vallas exteriores en exposición entre 20 de febrero-18 de marzo 2012 en Nueva York, con una instalación interior, como parte de la exposición Print/Out. The Museum of Modern Art (MoMA), New York NY. 19 Feb-14 May 2012. Com. Christopher Cherix. Fotógrafo: David Allison. Imagen cortesía del Museum of Modern Art @ Felix GonzalezTorres. Cortesía de la Felix Gonzalez-Torres Foundation



Ante las vallas, habría quien vería una imagen agradable, evocadora de dulces domingos por la mañana, de lento despertar en pareja. Habría quien, en cambio, sentiría la frialdad de esas sábanas abandonadas y de los huecos gemelos dejados por unos cuerpos cuyo paradero se desconoce. En todo caso, la ambigüedad de la imagen provocaría cierta sorpresa y más de una reflexión.

Hoy en día sabemos que estas marcas hacen referencia a unos cuerpos que en aquel momento estaban desapareciendo, de los que solo quedaba su ausencia: cuerpos de personas homosexuales que se infectaban de sida y morían silenciosamente, ignoradas por las noticias, invisibilizadas durante demasiado tiempo por un régimen de poder heterosexual que se negaba a aceptar la realidad de la crisis humanitaria. Porque, como señala Chambers-Letson, el

\section{Untitled, 1991. Valla publicitaria, dimensiones} variables según la instalación, $338^{a}$ Avenida/Calle 16 oeste, Manhattan, NY. 1 de 24 vallas exteriores en exposición en New York, con una instalación interior, como parte de la exposición Projects 34: Felix Gonzalez-Torres. The Museum of Modern Art (MoMA), New York, NY. 16 May-30 Jun 1992. (C) Felix GonzalezTorres. Cortesía de la Felix Gonzalez-Torres Foundation 


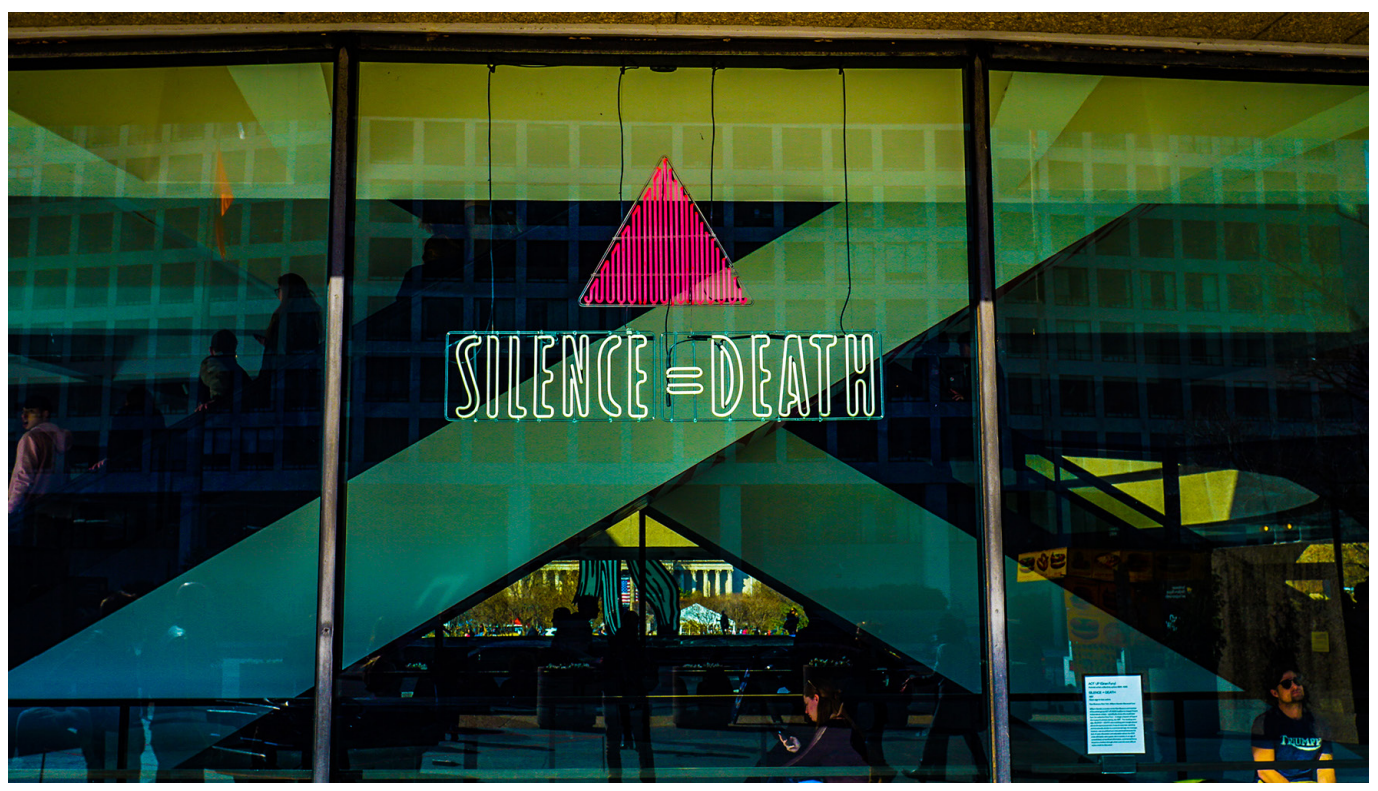

3. Símbolo Silence $=$ Death instalado en el Hirschhorn Museum, 2018. Fotofrafía de Ted Eytan, CC BY-SA 2.0

cuerpo conceptualizado y referenciado es el protagonista de la imagen, a pesar de no ser representado (2009: 561). Y aunque la falta se refiriera de manera particular a Ross, la pareja fallecida de Gonzalez-Torres, su ausencia adquiría un valor universal y compartido: el rastro de Ross es el de todas las personas que el sida nos ha robado.

Me interesa la estrategia que adopta Gonzalez-Torres en esta obra, la forma en que trae al espacio público un tema que incomodaba a las autoridades: la muerte por una horrible enfermedad de muchas personas, gran parte de ellas homosexuales ${ }^{1}$. Me interesa porque, a diferencia de otros artistas y activistas de la misma época que apostaron por una representación directa de su sexualidad, Gonzalez-Torres optó por un tipo de imagen que evocaba sin mostrar; que sugería sin exponer claramente sus intenciones. He denominado a esta decisión una estrategia translúcida, y en este artículo me propongo analizar cómo ha sido utilizada por artistas que, encontrándose fuera del régimen representativo oficial, han deseado ocuparlo sin dejar que este los controle.

Para estudiar la decisión estética y política de Gonzalez-Torres, conviene situarnos en el momento y en el contexto. Colectivos homosexuales se estaban estructurando y ganando visibilidad a raíz de las protestas contra la situación de crisis humanitaria, y entre ellos no faltaban artistas que utilizaban su familiaridad con el lenguaje formal para alcanzar este objetivo. El proyecto Silence $=$ Death (Silencio $=$ muerte) es un claro ejemplo de ello [3]. Esta imagen destaca por su simplicidad: un triángulo rosa con el vértice hacia arriba se recorta sobre un fondo negro, mientras las palabras «silence = death» denuncian el mortífero abandono que los enfermos estaban sufriendo por las autoridades. El triángulo rosa era una referencia directa al símbolo con el que los nazis marcaban a los gais, aunque en este caso su vértice era ascendente, renunciando así a la victimización e intentando transmitir energía positiva, fuerza y resistencia en vez de sometimiento. Esta imagen de diseño simple pero rotundo fue abrazada por el movimiento ACT UP, y pasó a convertirse en un símbolo colectivo de la lucha contra el sida (Finkelstein, 2013).

Otros optaron por imágenes más directas. Gran Fury, un colectivo que se creó a partir de ACT UP, llevó a cabo en 1988 la campaña Read my lips (Léeme los labios), en cuyo póster se reflejaba a dos hombres besándose. Este tipo de imágenes resultaban rompedoras en una sociedad heteropatriarcal y puritana que, especialmente fuera de las grandes ciudades como Nueva York donde se desarrollaba con más fuerza el movimiento, intentaba obviar la existencia de la homosexualidad, o la denunciaba directamente como obscena. 


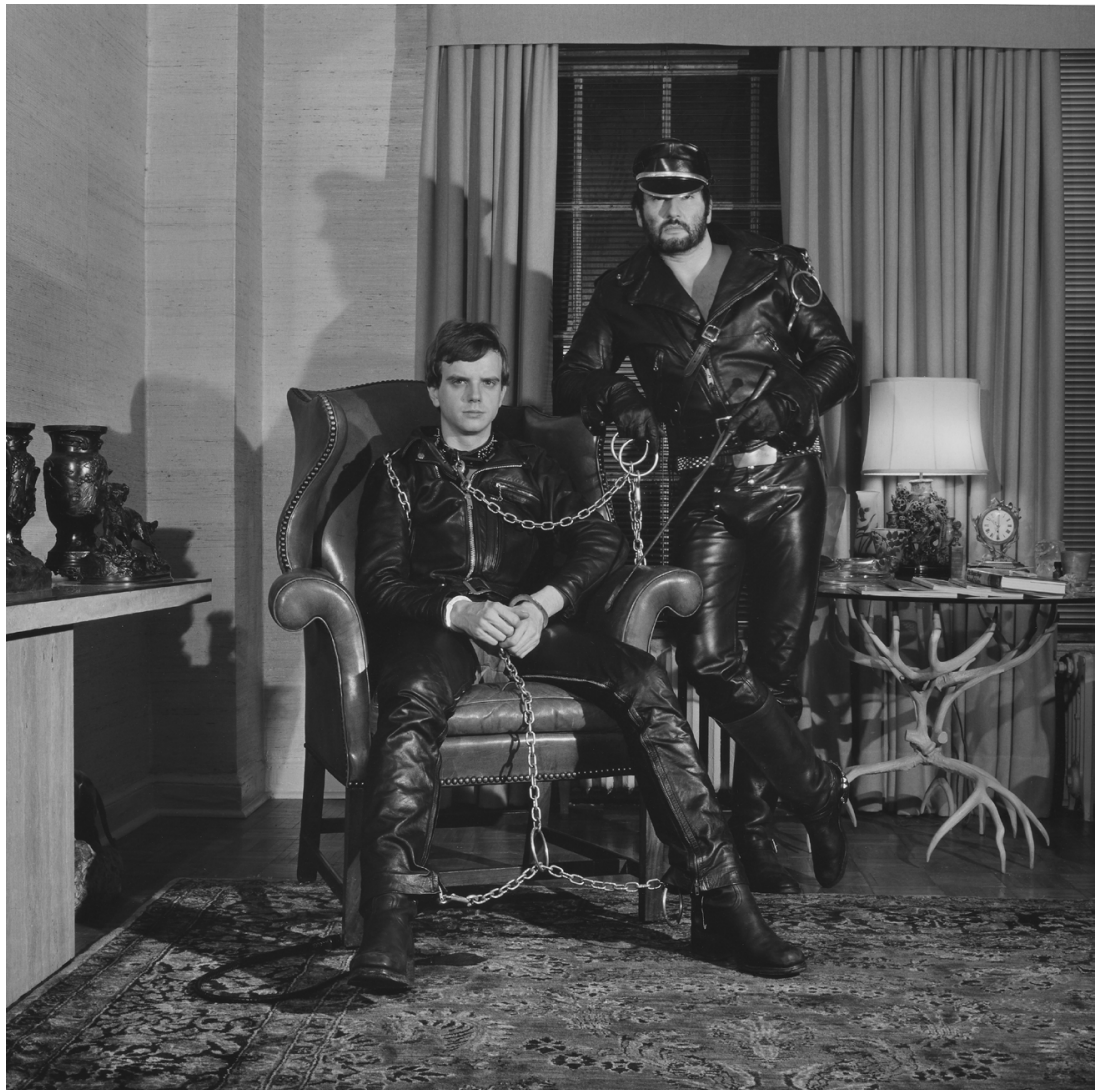

4. Robert Mapplethorpe, Brian Ridley and Lyle Heeter, 1979 @ C Robert Mapplethorpe Foundation. Utilizada con permiso
Víctima de estas denuncias fue la exposición The Perfect Moment (El momento perfecto), retrospectiva de Robert Mapplethorpe que se inauguró en Filadelfia en diciembre de 1988, tres meses antes de la muerte del artista, y viajó posteriormente a varias ciudades. Entre otras obras se mostraban las pertenecientes al $X$ Portfolio, una serie que representaba prácticas sadomasoquistas entre hombres [4]. Tras su paso sin mayor problema por Filadelfia y Chicago, la Corcoran Gallery de Washington anunció en junio de 1989 la suspensión de la exposición debido a presiones de grupos religiosos y liberales. La siguiente sede, el Contemporary Arts Center de Cincinnati, no renunció a la exposición que se inauguró en marzo de 1990, pero sufrió un duro ataque por parte de grupos conservadores, y se convirtió en el primer museo americano denunciado por obscenidad; su director, Dennis Barrie, tuvo que enfrentarse a juicio, aunque fue absuelto. La discusión en torno a la libertad de expresión y, consecuentemente, de la libertad sexual, ocupó la primera línea en todo el país².
Es en este contexto de confrontación en el que Felix Gonzalez-Torres instala sus imágenes de camas vacías por todo Nueva York. En lugar de representaciones explícitas de relaciones entre personas del mismo sexo, el artista evoca sentimientos compartidos como pueden ser el amor y la pérdida. Busca la cercanía de cualquier espectador, independientemente de su orientación sexual o su visión política.

Pero el objetivo final de esta búsqueda no se limita a crear empatía, sino que consiste en infiltrarse en los estamentos de poder (Chambers-Letson, 2009: 559); estamentos de poder en forma de régimen de imágenes (Rancière, 2006). En ese duro camino, el artista necesita protegerse: protegerse de convertirse en un blanco fácil de las fuerzas moralizadoras; de que sus imágenes sean clasificadas y retiradas en función del poder que estipula el derecho a la visibilidad. Nancy Spector relaciona la obra de Gonzalez-Torres a la resistencia al control visual, a la renuncia a objectivizar a sus sujetos (1995: 144). Y el propio artista indicó, refiriéndose a su obra Untitled (Perfect Lovers) [Sin título (Perfectos amantes)]: 
Dos relojes, uno junto al otro, constituyen una amenaza mucho mayor para el poder que una imagen de dos tíos haciéndose una mamada, porque ellos no pueden utilizarme como blanco de su contienda para destruir el significado. Va a ser muy difícil para los miembros del Congreso decirles a sus electores que están gastando dinero en la promoción del arte homosexual si todo lo que tienen para demostrarlo son dos enchufes, contiguos, o dos espejos juntos, o dos lámparas, una al lado de la otra (Spector, 1995: 75).

O una cama vacía con las sábanas revueltas y la marca de dos cuerpos.

Vemos que la elección de Gonzalez-Torres no se basa en una reivindicación exclusivamente formal o poética, sino que es muy consciente de la decisión política que se encuentra tras sus obras: desea burlar al sistema de control para instaurarse dentro del régimen y subvertirlo desde dentro. Desea reivindicarse, hacerse visible, sin por ello exponerse a ataques violentos. Para ello, articula una estrategia translúcida. Veamos a qué me refiero con este término.

\section{Translucidez y contraimagen}

La translucidez implica un punto intermedio entre transparencia y opacidad. Conlleva la presencia de una superficie visible sobre la que puede darse el reflejo; al mismo tiempo, supone un nivel de opacidad suficiente para dificultar que se traspase la superficie con la mirada, e impide una visión absoluta. Por ello, resulta un término adecuado para referirnos a las prácticas artísticas de aquellos individuos o colectivos que resultan vulnerables frente a una visibilidad total, y que optan por buscar una visibilidad opacada, una forma de estar presentes sin necesidad de ser transparentes.

Escribe Peggy Phelan siguiendo a Lacan:

La visibilidad es un callejón sin salida ${ }^{3}$ (Lacan, Four fundamental concepts: 93); convoca a la vigilancia y la ley; provoca voyeurismo, fetichismo, el apetito de posesión colonialista/ imperialista. $Y$ sin embargo mantiene un cierto atractivo político. Las políticas de la visibilidad tienen consecuencias prácticas; se puede marcar una línea entre una práctica (que alguien sea visto y leído) y una teoría (si eres visto es más difí- cil para «ellos» ignorarte, construir un canon punitivo); ambas estrategias pueden ser generativas (Phelan, 2003: 109-110; traducción propia).

Para aquellas personas que no han gozado de la posibilidad de influir en el régimen de las imágenes, la cuestión de la visibilidad es compleja, como apunta Phelan. Por una parte, ser visible es un requisito para ser sujeto político; bien lo sabían las sufragistas cuando se lanzaban a la calle a reclamar su lugar en el espacio urbano, político y visual. Al mismo tiempo, un sistema de la imagen definido en base a los cánones establecidos por un poder blanco, burgués, varón y adulto (BBVA) no resulta fácil de subvertir, puesto que son muchos sus recursos para establecer modos de construcción de la normatividad. El control desde la vigilancia y la ley se condensa en las fotografías realizadas por la policía a las personas detenidas y fichadas, clasificadas así como ajenas a la normatividad; y la exposición al apetito de posesión lo cristalizó Laura Mulvey en su fantástico «Placer visual y cine narrativo» (1975), que puede en gran medida ser extrapolado a buena parte del canon artístico occidental. Estos no son más que dos ejemplos de cómo la imagen es un arma de doble filo, al ser fácilmente utilizada por el sistema para objetivizar a quien se sirve de ella para reclamar su derecho a ser sujeto visible.

Utilizo el término «vulnerable» para referirme a aquellas personas que se encuentran en esta situación: excluidas de los espacios de visibilidad excepto cuando el régimen se apropia de su imagen para instrumentalizarlas. Entran dentro de este grupo muy diversos sujetos y colectivos, y tan diversos como los sujetos vulnerables son los sistemas de control que se ejercen sobre ellos.

En consecuencia, cuando hablo de estrategias translúcidas no me refiero a una forma concreta de hacer, a un decálogo o a una fórmula: se trata de un compendio de múltiples estratagemas, contextuales y situadas, difíciles de clasificar. Hay sin embargo unos elementos que todas tienen en común. Uno, fundamental, es que no se trata de crear contraimágenes, es decir, sistemas de representación que se sitúan de forma clara en el polo opuesto al régimen canónico. El póster Read my Lips de Gran Fury o el $X$ Portfolio de Mapplethorpe, por ejemplo, podría considerarse contraimágenes, puesto que rompen con las reglas del régimen, y se posicionan en el campo de lo no aceptable, 
lo no representable, lo inconcebible dentro de la visibilidad. En cambio, Untitled de Gonzalez-Torres juega con las reglas del canon para construir una imagen translúcida que pueda infiltrar lo no normativo dentro de la ley de la norma. Es una imagen transparente en cuanto no siembra dudas sobre qué vemos en la fotografía (una cama revuelta), pero lo suficientemente opaca como para posibilitar múltiples significados de lo que vemos; algunos de ellos permiten burlar al propio régimen y hackearlo.

Es necesario aclarar que las estrategias translúcidas no son por sí mismas ni más ni menos eficaces que las contraimágenes. Son otra forma de actuación con su capacidad perturbadora propia. El ejemplo de las obras de Mapplethorpe y Gonzalez-Torres muestran que ambas estrategias pueden provocar reacciones necesarias y complementarias.

Las contraimágenes suelen conllevar respuestas más inmediatas y directas, y esto las hace más fáciles de identificar. Sabemos que van a provocar reacciones. Las fotografías de Mapplethorpe y el ataque conservador que sufrieron desencadenaron un fuerte movimiento social con amplias repercusiones en el debate sobre la libertad de expresión y, consecuentemente, sobre las políticas de identidad (Kidd, 2004). Además, aunque no sea el caso del $X$ Portfolio, muchas de las contribuciones artísticas al activismo contra el sida, como los posters de Gran Fury, eran contingentes: su objetivo era impactar en el aquí y ahora, incluían referencias situadas geográfica y temporalmente, y no buscaban trascender en el tiempo.

El alcance del efecto de las obras de Gonzalez-Torres, en cambio, es más difícil de medir, puesto que su recepción fue individual y no provocó una respuesta organizada. A pesar de ello, podemos afirmar que su trabajo ha servido como símbolo y herramienta de memoria sobre la crisis del sida, y ha sido capaz de crear sentimientos de empatía hacia los enfermos entre públicos de diferentes culturas y generaciones. Los impactos se complementan, y ninguna de las obras podría haber provocado ambas respuestas por sí sola.

Una de las dificultades de las obras translúcidas consiste, precisamente, en medir su impacto. Esta dificultad no es exclusiva de estas obras, sino que afectan a gran parte de la producción artística contemporánea. El elemento que marca una diferencia en las obras con estrategias translúcidas es que, en contraposición a otras prácticas artísticas, estas tienen un objetivo político. Pretenden reivindicar, cambiar, alterar el status quo, aunque sea desplazándolo un solo milímetro. Comparten ese objetivo con las contraimágenes, pero la estrategia que adoptan es otra, y su translucidez, su renuncia a la transparencia, hace que la medida de su éxito sea también translúcida, más ambigua y difícil de clarificar. Al escapar a las reglas del régimen representacional, escapan también a sus formas de clasificación y evaluación.

El trabajo de Gonzalez-Torres es en ese sentido un ejemplo perfecto: obras críticas con el régimen heteropatriarcal que, al mismo tiempo, se integran con mucho éxito en el mercado del arte y su lógica capitalista, así como en el sistema del arte. Una de las dificultades que nos plantean algunas obras translúcidas es su complejidad de posicionamiento: frente a la postura inequívoca en la contracultura de Read my Lips de Gran Fury, Gonzalez-Torres busca ser parte de la institución del arte, aun siendo consciente, o precisamente por serlo, de la responsabilidad de ese mismo sistema en la construcción de un régimen excluyente y normativo. $Y$ en concordancia con su translucidez, resulta inexacto afirmar con contundencia que sus obras son únicamente productos que se ajustan a la especulación del mercado, o tan solo un ejercicio poético y estético de empatía, porque son ambas cosas al mismo tiempo.

Esta ambigüedad de la obra supondrá una razón de elogio por parte de algunos críticos, y de reproche para otros. Hay quien valora que frente a la cama vacía de Gonzalez-Torres cualquier persona puede compartir el sentimiento de pérdida de un ser querido, independientemente de su identidad sexual, cultural o de clase. Esta sería un atributo defendido por aquellos que resaltan la democracia y la universalidad de su obra, dos adjetivos habituales en los textos críticos. Sin embargo, para algunas personas que vivieron la lucha contra el sida como un proceso de reivindicación de una identidad queer, la obra de Gonzalez-Torres amenaza con perder la especificidad del sufrimiento; a través de la universalización del dolor, puede blanquear que este fue padecido por unos colectivos concretos con unas características que los hicieron más vulnerables e ignorados. Como escribió Douglas Crimp refiriéndose a la película Filadelfia, parece que «tienes que prescindir de lo que hace marica a un marica para conseguir que todo el mundo sienta pena por el hecho de que él vaya a morir» (2005: 125). 


\section{En la oscilación está la fuerza}

En algunos momentos me he referido a la obra en general de Gonzalez-Torres como translúcida, puesto que son muchas las piezas que nacen de esta forma de hacer: desde las montañas de caramelos hasta las parejas de objetos idénticos, apreciamos el equilibrio entre lo que se ve y lo que se sugiere en la mayoría de su trabajo. No obstante, su caso es singular, ya que la estrategia translúcida no tiene por qué ser una constante en la trayectoria de un o una artista; no es un "estilo». Al contrario, puede ser una estrategia que responda a un contexto y un momento precisos, y la posibilidad de oscilar entre ella y las contraimágenes no es una incoherencia, sino una ventaja.

Un buen ejemplo de oscilación es el propio Mapplethorpe. Hemos analizado su X Portfolio como contraimagen, pero esa definición resultaría errónea para la mayor parte de su obra, incluyendo los $Y$ y $Z$ Portfolio, dedicados respectivamente a imágenes de flores y a desnudos de hombres negros, que a menudo se exponen con el $X^{4}$. En estos y muchos otros de sus trabajos los críticos han resaltado su tratamiento clásico de las formas; los contrastes de luz en la fotografía en blanco y negro dan un carácter volumétrico a los cuerpos que recuerdan a la escultura antigua. Así, incluso podríamos abordar algunas de sus obras desde la óptica de la translucidez, y analizar en qué manera un lenguaje canónico es utilizado para la representación de objetos que no lo son en absoluto, como los cuerpos de hombres deseados por otros hombres ${ }^{5}$.

Para analizar la oscilación entre la estrategia translúcida y la creación de contraimágenes me gustaría introducir un nuevo perfil de sujetos vulnerables: el de las mujeres. He mencionado antes que las sufragistas intentaron ocupar las calles para exigir ser visibles en ambos regímenes representativos: el de la imagen y el político. Y es cierto que desde entonces muchas mujeres aparecen en los espacios públicos, pero por lo general, a través de representaciones que siguen las pautas normativas del sistema heteropatriarcal, y que a menudo están al servicio del intercambio capitalista, como es la publicidad. Este es un claro ejemplo de apropiación de la imagen por parte del régimen, y desde el feminismo y las prácticas artísticas son muchos los intentos de subvertir este orden.

Dentro de esta tradición contestataria se sitúa Señora Polaroiska, un colectivo formado por Alaitz Arenzana y
María Ibarretxe localizado en Bilbao. A ellas debo mi primer acercamiento al concepto de translucidez, puesto que fue estudiando su película de 2009 Exhibition 19 como observé el juego entre la transparencia y la opacidad. En este caso, las autoras deseaban hacer visibles en el espacio público a una serie de mujeres; sin embargo, era su objetivo escapar de las convenciones canónicas de representación del cuerpo femenino.

Para lograr su objetivo, las hacía fluctuar entre la transparencia y la opacidad. La transparencia se reconocía en que todas las protagonistas se figuraban a sí mismas: las veíamos con sus ropas, en sus puestos de trabajo habituales. En ese sentido hablamos de un retrato colectivo. Sin embargo, sobre esta trasparencia se elaboraban una serie de tramas opacas que hacían la imagen translúcida. Por una parte, se rehuía el hilo argumental tradicional, y se engarzaban una serie de imágenes que podían construir muy diversas lecturas, ninguna de ellas evidente. Además, se intercalaban imágenes rutinarias de las jornadas laborales de estas mujeres con otras sorprendentes, en las que aparecían realizando acciones misteriosas e inesperadas. Finalmente, las artistas combinaban planos abiertos de espacios urbanos con otros muy cerrados de partes aisladas de los cuerpos representados

[5] y [6], que no ofrecían una visión diáfana de lo que estaba sucediendo, sino la sensación de estar siempre accediendo a una realidad parcial (Barcenilla, 2016).

Así, este conjunto de decisiones estéticas y narrativas permitían a Señora Polaroiska proponer, en colaboración con las protagonistas, otros imaginarios de mujeres posibles; esta estrategia de translucidez les permitía deslizarlas dentro del régimen existente, sin suponer una ruptura absoluta.

La elección de esta estrategia se debe a los sujetos representados, las 19 mujeres de Varsovia que protagonizan la película. Todas ellas eran mujeres trabajadoras, la mayoría de ellas en servicios, y por lo tanto, se encontraban presentes en el espacio físico urbano. Sin embargo, al realizar tareas periféricas y no adecuarse al canon de mujer que se proyecta en los espacios públicos, se diluían en el marco del régimen representacional; la representación normativa que suele realizarse de «la mujer» las excluía, y las dejaba en un terreno de nadie, en el que su presencia no aseguraba una representación subjetiva. Señora Polaroiska querían ensanchar este imaginario, hacerlas aparecer ofreciéndoles un tipo de imagen con el que ellas, como protagonistas, pudieran 

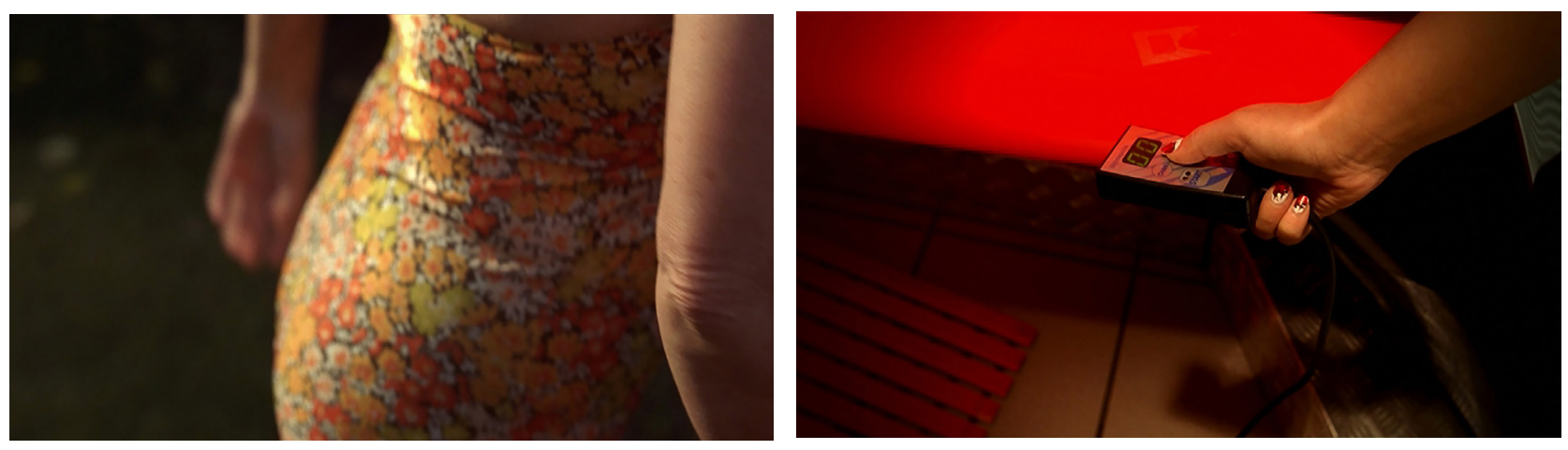

5 y 6. Señora Polaroiska, stills de Exhibition 19, 2009. Cortesía de las artistas

identificarse. La estrategia translúcida ofrecía las herramientas para llevarlo a cabo.

Sin embargo, en trabajos posteriores con objetivos similares, Señora Polaroiska ha optado por crear contraimágenes. Un ejemplo de ello sería la película Pilota Girls de 2012, en la que una mujer joven juega a pelota a mano, un deporte tradicional vasco y eminentemente masculino, contra las fachadas de edificios públicos en Bilbao. Una vez más las artistas buscaban la visibilidad como arma de legitimación, en este caso la de las mujeres pelotaris. Para ello, en vez de grabar a la protagonista en un frontón, la localización habitual de este deporte, optaron por situarla en el espacio público: la hicieron invadir la ciudad, con una actitud evidentemente agitadora.

La estructura de esta película es más sencilla que la de Exhibition 19. La narratividad responde a una formulación más clásica: se da comienzo a la obra enfocando a la protagonista junto con la pelota; no se reservan sorpresas, y el título también resulta directo. A continuación, y durante la parte central de la pieza, la pelotari se desplaza por la ciudad atacando diferentes superficies de edificios públicos con la bola, andando entre coches, saltando barreras; es decir, subvirtiendo el orden espacial urbano establecido [7]. Como última secuencia, aparece frente al Frontón Bizkaia, el recinto principal de Bilbao, contra el que lanza la pelota. En vez de mostrar cómo esta golpea sus muros, las artistas nos ofrecen un primer plano de las gafas de sol de la pelotari en las que se refleja una explosión.

El sonido también difiere mucho de Exhibition 19. En esta pieza se recurría al ruido ambiente y a sutiles sonidos de fondo, que variaban adecuándose a cada cambio de lo- calización. En el caso de Pilota Girls, sin embargo, la escena de presentación se realiza con un sonido de fondo, pero en cuanto la protagonista pasa a la acción resuena el tema Sabotage de Beastie Boys, que acompaña la acción en toda su duración e impregna la pieza, no dejando lugar a dudas sobre su posicionamiento.

Para comprender el cambio de estrategia entre las dos piezas resulta necesario observar no solo las coincidencias en sus objetivos, sino sobre todo las divergencias en el punto de partida: el lugar de sus sujetos dentro del régimen de representación. Las mujeres de Exhibition 19 deben trastocar una imagen ya existente que objetualiza, que homogeniza a todas las mujeres dentro de un arquetipo de «mujer», que ofrece una representación subjetiva propia a las diversas mujeres que habitan el espacio. En el caso de Pilota Girls se parte de una ausencia absoluta: la falta de mujeres jugadoras de pelota a mano en el régimen de representación. De hecho, a principios del siglo XX se comenzó a construir una división por género en muchas prácticas tradicionales vas$\mathrm{cas}^{6}$, y las mujeres quedaron relegadas al juego de pelota con raqueta, no pudiendo ejercer ni la pelota a mano ni la cesta punta. Así, no hay una imagen que ensanchar, que ocupar, ya que no hay imagen de la que partir. La imagen del pelotari se construye por definición desde el arquetipo del hombre y, por lo tanto, el simple hecho de mostrar a una mujer jugando a pelota a mano entra dentro de lo inconcebible. Una mujer pelotari solo puede ser una contraimagen y, consciente de ello, Señora Polaroiska sitúa a su protagonista perturbando el espacio público con su presencia y su acción; si su existencia es por sí misma una subversión, que su actitud sea igualmente subversiva. 


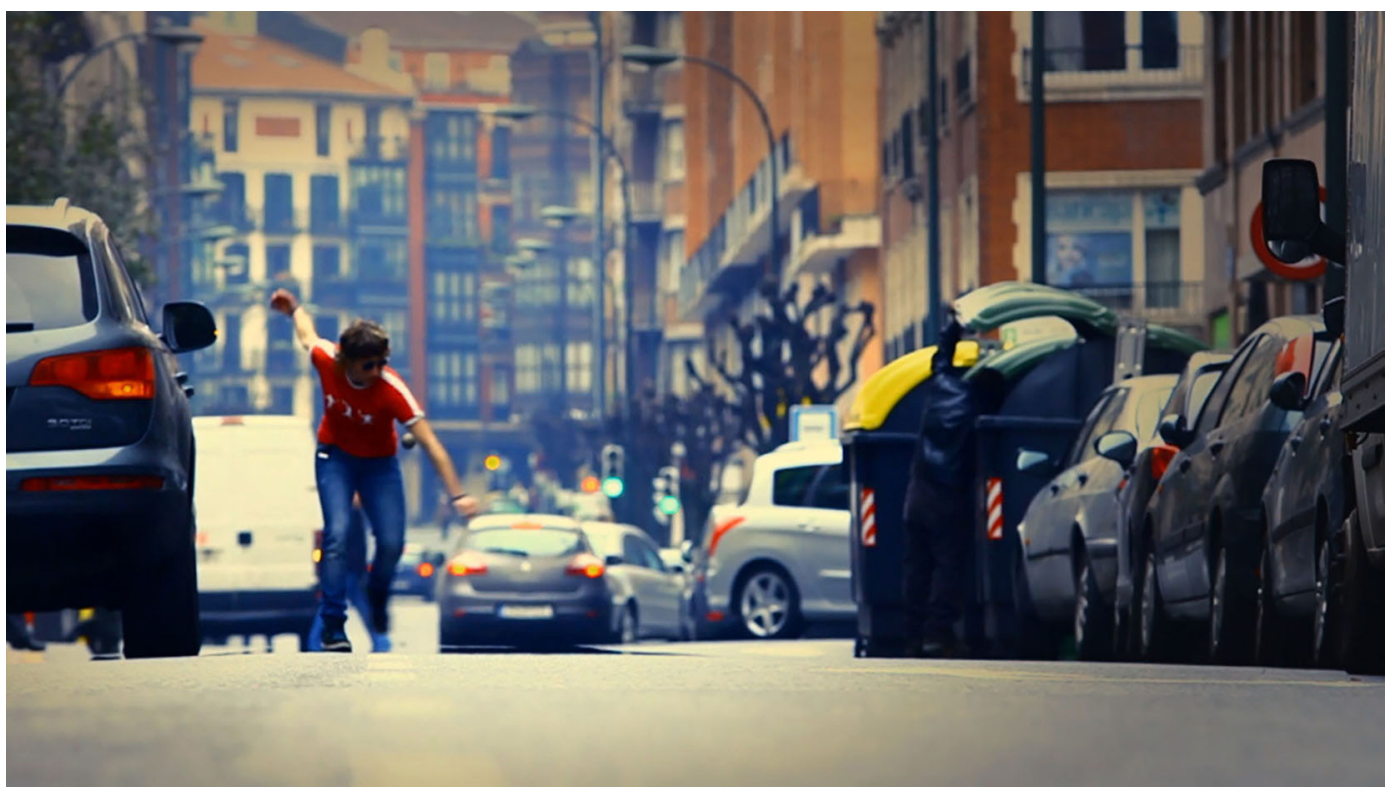

7. Señora Polaroiska, still de Pilota Girls, 2012. Cortesía de las artistas

\section{Conclusiones}

Vemos, por lo tanto, que la estrategia translúcida es un útil para la agitación menos directo y contingente que las contraimágenes, pero que no por ello ha de ser menos efectivo; responde a situaciones en que resulta preferible evadir el control del régimen representacional, de infiltrarlo en vez de enfrentarlo. Su combinación con la creación de contraimágenes puede ofrecer una forma de disidencia más compleja y mutante, que resulta difícil de aprehender por los sistemas de representación hegemónicos.

Ambas formas de actuar desde la imagen cuentan con ventajas y desventajas. La contraimagen puede provocar una respuesta inmediata e incluso desencadenar un movimiento social articulado, como fue el caso del $X$ portfolio. Sin embargo, también se expone de manera más evidente a la censura y, en consecuencia, a no llegar a afectar al espacio público. La estrategia translúcida, en cambio, corre el riesgo de que su efecto permanezca más difuminado; y sin embargo, tiene al mismo tiempo la capacidad de influir en públicos a quien las contraimágenes no llegan o no logran apelar.
De hecho, una cuestión fundamental es el tipo de público al que se dirige cada forma de representación. A menudo las contraimágenes buscan crear un lazo de unión dentro de la propia comunidad de sujetos vulnerables, tejer un sentimiento de pertenencia que incluso se transforme en organización colectiva contra el régimen. Este lazo empodera al colectivo, pero también puede suponer una posible reacción de rechazo por quienes no forman parte de él. En contraste, la estrategia translúcida tiene la potencialidad de acercarse a públicos externos al grupo vulnerable y buscar su empatía, o simplemente provocar en ellos interés por aquello que les resulta ajeno. Apela a un nivel más individual, por lo que la identidad del grupo receptor se difumina pero también se amplía.

Así, una combinación de ambas estrategias aplicadas de manera contextual y situada puede comportar un mayor alcance, trascendiendo públicos específicos y provocando mayor impacto social. Al mismo tiempo, espero que estas definiciones puedan ofrecernos a las historiadoras del arte una herramienta para comprender cómo actúan y afectan al régimen de imágenes hegemónico las prácticas artísticas realizadas desde la vulnerabilidad. 


\section{Notas}

* Este artículo forma parte del proyecto de investigación «Prácticas de la subjetividad en el arte contemporáneo» (HAR2016-75662P) financiado por el MINECO/Ministerio de Ciencia, Innovación y Universidades.

1 Por la naturaleza de la obra me voy a centrar en el colectivo homosexual. Sin embargo, el sida también provocó la muerte de muchas otras personas de colectivos vulnerables, por ejemplo, prostitutas y drogodependientes, que por situarse en los márgenes de la sociedad fueron también invisibilizadas. Aunque desde las artes ha habido acercamientos a estas realidades, al no organizarse de manera colectiva ni construir un imaginario reivindicativo tan claro, han estado menos presentes. No por ello debemos olvidarlas.

2 La presión que grupos conservadores y homófobos ejercieron sobre el National Endowment for the Arts (NEA), la agencia federal de apoyo a las artes, provocaron que el ICA de Filadelfia donde se generó la exposición fuera puesto a prueba durante cinco años a partir de 1989 y que todas sus exposiciones fueran supervisadas. Este conflicto llevó a lo que se ha conocido como "guerras culturales" (culture wars), sobre la que existe numerosa literatura. Destacaría el estudio de Kidd (2004).

3 Phelan utiliza aquí la palabra "trap», que puede traducirse como «trampa", pero al presentar la propia autora los lados buenos y malos de la visibilidad, me decanto por la acepción "callejón sin salida", en el sentido de enredo, de moneda con dos caras. Por supuesto, se trata de una interpretación discutible.

4 Me gustaría señalar que cuando estas obras se presentan en la misma sala, combinadas entre sí, es la propia estrategia expositiva la que se vuelve translúcida. Queda pendiente para un próximo artículo el estudio de estrategias translúcidas en el espacio instalacional.

5 Al no ser el corpus de Mapplethorpe el objetivo de este análisis, no estudiaré en profundidad la cuestión de la translucidez en su trabajo. Dicho estudio debería hacerse pieza a pieza, con un análisis contextual apropiado, y dudo que el término valiera para todas ellas. Algunos de sus autorretratos o obras como Phillip (1979) podrían encajar en esta estrategia; en cambio, en el caso del Z Portfolio se ha criticado con coherencia la fetichización de los hombres negros (valga como ejemplo Nixon, 2019). Esto sitúa a Mapplethorpe en el espacio del poder, en la mirada del régimen, que en vez de ofrecer a los vulnerables la posibilidad de ejercer su subjetividad a través de la imagen, los objetualiza, se apropia de ellos.

6 Oier Araolaza ha estudiado este fenómeno en el campo de la danza (2018 y su tesis doctoral defendida en 2020). En la conferencia que impartió en UEU en Eibar el 11 de septiembre de 2020 mostró la forma en que esta división afecta a la pelota.

\section{Bibliografía}

ARAOLAZA, Oier (2018), «El último aurresku. Género, danza y nacionalismo vasco a comienzos del siglo XX», Pasado y Memoria. Revista de Historia Contemporánea, n. ${ }^{\circ} 17$, pp. 235-257.

BARCENILLA, Haizea (2016), «Rompe la ventana: Exposición y ocultación en Exhibition 19 de Señora Polaroiska», en PEYRAGA, Pascale, GAUTREAU, Marion, PEÑA ARDID, Carmen y SOJO GIL, Kepa (eds.), La imagen translúcida en los mundos hispánicos, Orbis Tertius, Bruselas, pp. 491-512.

CHAMBERS-LETSON, Josh Takano (2009), «Contracting Justice: The Viral Strategy of Felix Gonzalez-Torres», Criticism, vol. 51, n. ${ }^{\circ} 4$, pp. 559-587.

CRIMP, Douglas (2005), Posiciones críticas. Ensayos sobre las políticas de arte y la identidad, Akal, Madrid.

FINELSTEIN, Avram (2013), «The Silence=Death poster». En <https://www.nypl.org/blog/2013/11/22/silence-equals-death-poster> (fecha de consulta: 20-8-2020).

KIDD, Dustin (2004), «Sexual Politics in the Defense of Art: Culture Wars, Mapplethorpe, and the Road from Formalism to Identity Politics", Research in Political Sociology, vol. 13, pp. 79-112.

MULVEY, Laura (1975), «Visual Pleasure and Narrative Cinema», Screen, vol. 16, n. ${ }^{\circ}$ 3, pp. 6-18.

NIXON, Lindsay (2019), «Distorted Love: Mapplethorpe, the Neo/Classical Sculptural Black Nude, and Visual Cultures of Transatlantic Enslavement», Imaginations, vol. 10, n. ${ }^{\circ}$, pp. 295-324.

PHELAN, Peggy (2003), «Broken Symmetries: Memory, Sight, Love», en JONES, Amelia (ed.), The Feminism and Visual Culture Reader, Routledge, London, pp. 105-115.

RANCIÈRE, Jacques (2006), The Politics of Aesthetics, Continuum, Londres.

SPECTOR, Nancy (1995), Felix Gonzalez-Torres, Guggenheim Museum, Nueva York. 